\title{
Microprobe study of Portuguese ancient silver coins of uncertain provenance
}

Cruz, J. ${ }^{* * *, * * *}$, Corregidor, V. ${ }^{* * * * * *}$ and Alves, L.C. ${ }^{* * * * * *}$

* Departamento de Física, Faculdade de Ciências e Tecnologia, Universidade Nova de Lisboa, 2829-516 Caparica, PORTUGAL.

** Campus Tecnológico e Nuclear, Instituto Superior Técnico, Universidade de Lisboa, E.N. 10, 2686-953 Sacavém, PORTUGAL.

*** Centro de Física Nuclear da Universidade de Lisboa, Av. Prof. Gama Pinto, 1649-003 Lisboa, PORTUGAL.

Email: jdc@fct.unl.pt

Ion Beam Analytical (IBA) techniques such as Particle Induced X-ray Emission (PIXE) and Elastic Backscattering Spectrometry (EBS) are finding increasing applications in the study of ancient coins [1] because they are non-destructive and can determine the coin chemical fingerprint down to the ppm range, which in some cases can be related with the ore provenance or the metal purification process, thus giving information about the fabrication period. In ancient coins, surface inhomogeneities created by centuries of corrosion growth, require a micro beam to characterize them. The analysis of $\mu$-PIXE and $\mu$-EBS spectra taken simultaneously allows to differentiate the superficial corrosion layer from the bulk, giving elemental surface composition distribution and elemental depth profiling, respectively. Using 1.0 and $2.0 \mathrm{MeV}$ proton beams from the nuclear microprobe (resolution $3 \times 4 \mu \mathrm{m}^{2}$ ) located at the Ion Beam Laboratory at CTN (Sacavém - Portugal), this approach was used to try to clarify about the authenticity of two XVI century Portuguese $91.6 \%$ wt silver (stipulated by decree of law) coins (Fig. 1) as the stylistic analysis by numismatic experts was not conclusive. Three coeval genuine Portuguese coins were also studied and served as a comparison.

2D-PIXE maps (as shown in Fig. 2) were acquired for all coins, followed by point analysis $\left(3 \times 4 \mu \mathrm{m}^{2}\right)$ in areas with thicker (higher $\mathrm{Fe}$ and $\mathrm{Br}$ content) and thinner (higher $\mathrm{Ag}$ and $\mathrm{Cu}$ content) corrosion layer.

Figure 3 shows fitted $\mu$-PIXE and $\mu$-EBS spectra taken simultaneously using a $1.0 \mathrm{MeV}$ proton beam. These fits performed on all five coins showed that:

a) major elements $\mathrm{Ag}$ and $\mathrm{Cu}$ : genuine coins have $\approx 95 \mathrm{wt} \%$ in $\mathrm{Ag}$ and $\approx 5 \mathrm{wt} \%$ in $\mathrm{Cu}$ homogenously distributed, while the two coins of uncertain provenance show $\approx 70-80 \mathrm{wt} \%$ in $\mathrm{Ag}$ and $\approx 20-30 \mathrm{wt} \%$ in $\mathrm{Cu}$;

b) trace elements $\mathrm{Au}$ and $\mathrm{Bi}$ (which are related with ore provenance): not detected on all coins, but when detected the concentration is around $0.05 \mathrm{wt} \%$;

c) trace element $\mathrm{Pb}$ (which is related with $\mathrm{Ag}$ refining process): detected on all coins, with $\approx 0.2 \mathrm{wt} \%$ quantified.

From these results it was not possible to give a definite answer about the authenticity of the two coins of uncertain provenance. The low content in $\mathrm{Ag}$ is very uncommon in ancient coins, even more knowing that $\mathrm{Ag}-\mathrm{Cu}$ alloys get surface enriched in silver, as observed for the genuine coins. However, in terms of trace elements, data are consistent with genuine coins.

V. Corregidor acknowledges the funding support from the FCT-Ciência program. The work was partially supported by FCT-Portugal (PEST-OE/FIS/UI0275/2011).

[1] Guerra, M.F. et al., Nucl. Instr. and Meth. in Phys. Res. B, 240, 505-511, 2005. 

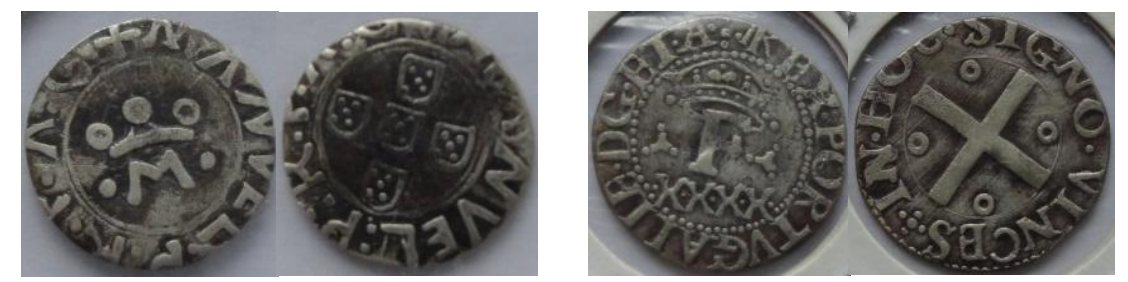

Figure 1. Obverse and reverse of the two analyzed coins of uncertain provenance. Left panel: Portuguese 5 Reais of King Manuel I (1495-1521); Right panel: Portuguese XXXX Reais of King Filipe I (1580-1598).
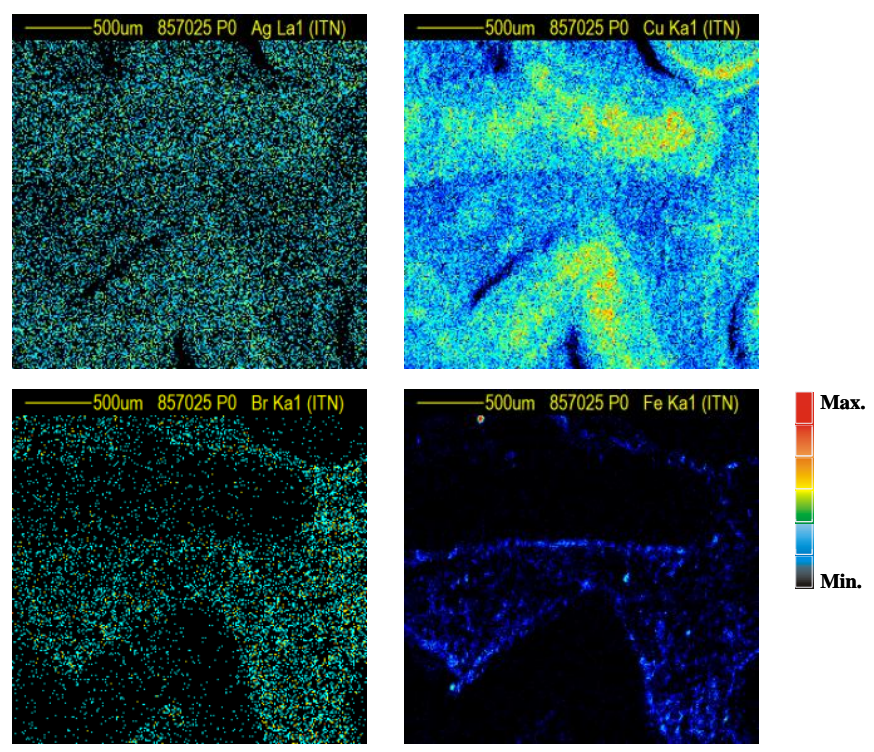

Figure 2. 5 Reais of King Manuel I coin: 2D-PIXE maps of $\mathrm{Ag}, \mathrm{Cu}, \mathrm{Br}$ and $\mathrm{Fe}\left(2640 \times 2640 \mu \mathrm{m}^{2}\right)$.
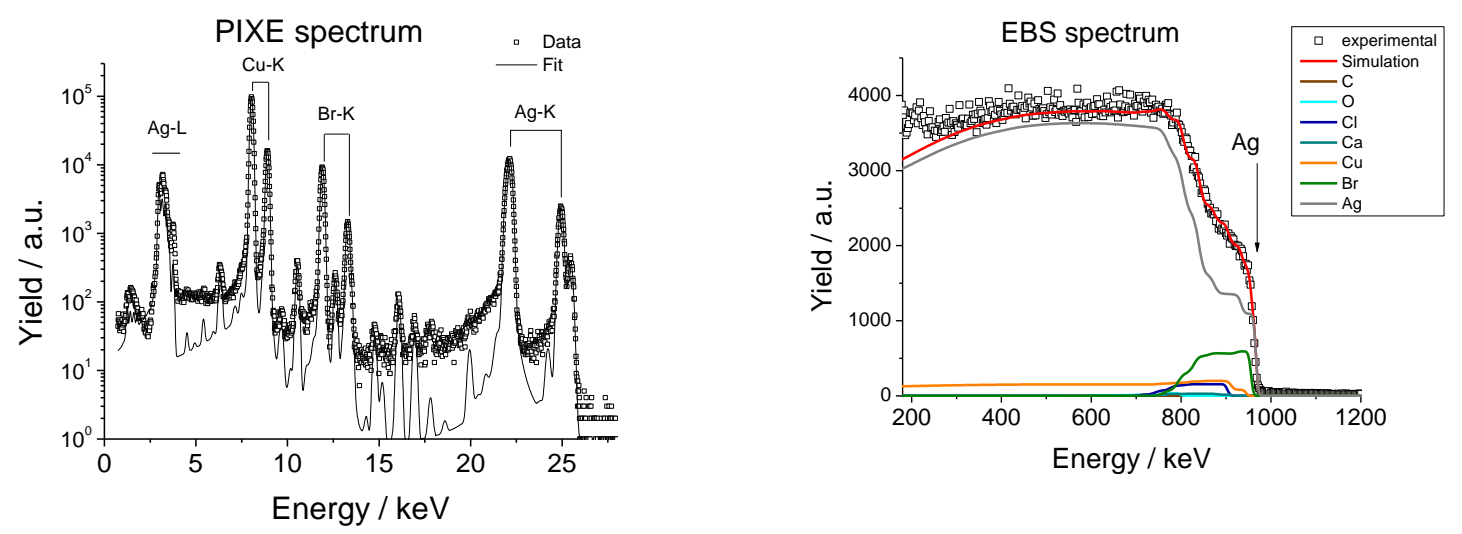

Figure 3. Fitted $\mu$-PIXE and $\mu$-EBS spectra, acquired on a corroded area of the 5 Reais coin using a $1.0 \mathrm{MeV}$ proton beam. PIXE spectrum clearly shows the presence of $\mathrm{Br}$ in this area while the EBS spectrum fit ascertains the corroded area thickness (signal from Br layer results in the lower surface layer signal of Ag). 